\title{
Growth patterns in children with spinal muscular atrophy
}

\author{
Ramona De Amicis ${ }^{1 *} \mathbb{D}$, Giovanni Baranello ${ }^{2,3}$, Andrea Foppiani ${ }^{1}$, Alessandro Leone ${ }^{1}$, Alberto Battezzati ${ }^{1}$, \\ Giorgio Bedogni ${ }^{1}$, Simone Ravella', Ester Giaquinto ${ }^{4}$, Chiara Mastella $^{5}$, Caterina Agosto ${ }^{6}$, Enrico Bertini ${ }^{7}$, \\ Adele D'Amico ${ }^{7}$, Marina Pedemonte ${ }^{8}$, Claudio Bruno ${ }^{9}$, Jonathan C. Wells ${ }^{10}$, Mary Fewtrell ${ }^{10}$ and \\ Simona Bertoli ${ }^{1,11^{*}}$
}

\begin{abstract}
Background: Spinal muscular atrophy (SMA) is a neuromuscular disorder characterized by muscle atrophy and weakness. SMA type 1 (SMA1) is the most severe form: affected infants are unable to sit unaided; SMA type 2 (SMA2) children can sit, but are not able to walk independently. The Standards of Care has improved quality of life and the increasing availability of disease-modifying treatments is progressively changing the natural history; so, the clinical assessment of nutritional status has become even more crucial. Aims of this multicenter study were to present the growth pattern of treatment-naive SMA1 and SMA2, and to compare it with the general growth standards.

Results: Body Weight $(B W, \mathrm{~kg})$ and Supine Length $(\mathrm{SL}, \mathrm{cm})$ were collected using a published standardized procedure. SMA-specific growth percentiles curves were developed and compared to the WHO reference data. We recruited 133 SMA1 and 82 SMA2 (48.8\% females). Mean ages were 0.6 (0.4-1.6) and 4.1 (2.1-6.7) years, respectively. We present here a set of disease-specific percentiles curves of BW, SL, and BMI-for-age for girls and boys with SMA1 and SMA2. These curves show that BW is significantly lower in SMA than healthy peers, while SL is more variable. BMI is also typically lower in both sexes and at all ages.

Conclusions: These data on treatment-naïve patients point toward a better understanding of growth in SMA and could be useful to improve the clinical management and to assess the efficacy of the available and forthcoming therapies not only on motor function, but also on growth.
\end{abstract}

Keywords: Spinal muscular atrophy, Growth, Percentiles, Nutritional status

\section{Introduction}

Spinal muscular atrophy (SMA) is a rare neuromuscular disorder characterized by progressive muscle atrophy, generalized weakness, and paralysis [1]. The classical form is a monogenic disorder, due to mutations in the Survival of Motor Neuron 1 (SMN1) gene that leads to degeneration of alpha motor neurons in the spinal cord

\footnotetext{
*Correspondence: ramona.deamicis@unimi.it; simona.bertoli@unimi.it ${ }^{1}$ International Center for the Assessment of Nutritional Status (ICANS), Department of Food, Environmental and Nutritional Sciences (DeFENS), University of Milan, Via Sandro Botticelli 21, 20133 Milan, Italy Full list of author information is available at the end of the article
}

[2]. SMA has an incidence of about 1 in 6000 to 1 in 10,000 live births [3] and is categorized into five different phenotypes based on the age of onset and the highest level of motor function achieved [4].

The most severe form compatible with life is type 1 (SMA1): SMA1 infants show the first symptoms at birth or before 6 months of age and are unable to sit unsupported $[5,6]$. They are affected by the highest burden of comorbidities, including progressive bulbar dysfunction, respiratory failure and gastrointestinal symptoms, that tend to hamper their nutritional management and can lead to failure to thrive [7-10]. The onset of symptoms original author(s) and the source, provide a link to the Creative Commons licence, and indicate if changes were made. The images or other third party material in this article are included in the article's Creative Commons licence, unless indicated otherwise in a credit line to the material. If material is not included in the article's Creative Commons licence and your intended use is not permitted by statutory regulation or exceeds the permitted use, you will need to obtain permission directly from the copyright holder. To view a copy of this licence, visit http://creativecommons.org/licenses/by/4.0/. The Creative Commons Public Domain Dedication waiver (http://creativeco mmons.org/publicdomain/zero/1.0/) applies to the data made available in this article, unless otherwise stated in a credit line to the data. 
in SMA type 2 (SMA2) typically occurs between 7 and 18 months [11], and affected children that can achieve the ability to sit without support but are not able to walk independently. SMA2 children can show swallowing and chewing difficulties, along with respiratory problems that can require mechanical ventilation [11]. The nutritional status of the two forms has been reported to be quite the opposite: SMA1 children tend to be underweight $[8,9]$, while SMA2 children can be overweight or even obese [12], although undernutrition is also reported in a percentage of cases $[7,8,12,13]$.

Since the publication and implementation of the Standards of Care (SoC) for SMA in 2007 and 2018 [5, 14] there has been an improvement in prognosis and survival for patients with SMA as a result of a more proactive approach in the management of the disease and its complications $[5,14]$. In addition, the increasing availability of disease-modifying treatments, including the antisense oligonucleotide nusinersen, the gene replacement therapy Onasemnogene Abeparvovec, and, more recently, the small molecule risdiplam, is progressively changing the natural history of the disease $[6,15,16]$.

As body composition of children with SMA differ from those of the normal population, with SMA patients showing decreased lean body mass and increased fat mass [5, $9,10]$, comparison of BMI with growth references for the general pediatric population may not reflect the nutritional status. Although the use of standard growth charts has been suggested for monitoring longitudinal growth in SMA children, the clinical assessment of their growth and nutritional status would be improved by the availability of disease-specific growth percentiles curves. This will also allow evaluation of the effects of the increasingly available novel disease-modifying treatments on growth and nutritional status.

Hence, the aim of this study is to present for the first time the growth pattern of a large sample of treatmentnaïve SMA 1 and 2 children and to compare it with the reference values for the general pediatric population to clarify possible differences.

\section{Methods}

\section{Participants and study design}

Participants were recruited, between April 2015 and May 2018, from 5 clinical SMA referral centers in Italy (SAPRE-UONPIA, Fondazione IRCCS $\mathrm{Ca}$ ' Granda Ospedale Maggiore Policlinico, Milan; UO Neurologia dello Sviluppo, Fondazione IRCCS Istituto Neurologico Carlo Besta, Milan; Dipartimento di Salute della Donna e del Bambino, Università di Padova; Unità di Malattie Neuromuscolari e Neurodegenerative, Laboratorio di Medicina Molecolare, Dipartimento di Neuroscienze e Neuroriabilitazione, IRCCS Ospedale Pediatrico
Bambino Gesù, Rome; IRCCS Istituto Giannina Gaslini, Genoa), all involved in a large multicenter observational study in SMA children.

Inclusion criteria were:

- Genetic confirmation of 5q-autosomal recessive SMA (either due to homozygous deletions or to compound heterozygous mutations in the SMN1 gene) [5];

- clinically confirmed diagnosis of SMA1 or SMA2 [17];

- age 0-11.99 years;

- clinical management according to the best supportive care based on the Consensus Statement for SoC in SMA [5, 17];

- absence of acute medical conditions in the 15 days before the assessment;

- not involved in any experimental pharmacological trials at the time of the assessment.

Each child underwent the anthropometric measurements [body weight (BW, $\mathrm{kg}$ ), supine length $(\mathrm{SL}, \mathrm{cm})$ ] at one of the following sites: the International Center for the Assessment of Nutritional Status (ICANS), University of Milan; Dipartimento di Salute della Donna e del Bambino, Università di Padova; Unità di Malattie Neuromuscolari e Neurodegenerative, Laboratorio di Medicina Molecolare, Dipartimento di Neuroscienze e Neuroriabilitazione, IRCCS Ospedale Pediatrico Bambino Gesù, Rome; Dipartimento di Neuroscienze e Riabilitazione, IRCCS Istituto Giannina Gaslini, Genoa.

The study was approved by the Ethics Committee of the University of Milan (n.7/16), accepted by the other institutional partners and complied following the Helsinki declaration. The parents, on behalf of their children, gave their written informed consent to the study.

\section{Study variables}

Demographic, clinical, and anthropometric variables were collected. The demographic variables included age at study date and sex. Clinical variables included type of breathing: spontaneous compared with mechanical ventilation (non-invasive mechanical ventilation or invasive ventilation-tracheostomy), type of feeding (oral compared with nasogastric tube or gastrostomy). The clinical variables were collected by pediatric neurologists $(\mathrm{GiBa}$, $\mathrm{CA}, \mathrm{AD}, \mathrm{MP}, \mathrm{CB}) 1$ day before nutritional assessment.

\section{Anthropometric measurements}

In each center, all anthropometric measurements were collected by the same dieticians who attended a 1-day training workshop and used standardized measuring procedures [18]. The measurements were taken in a standard 
setting at the same time, with the child undressed and in the fasting state.

According to the WHO child growth standards, BW was collected to the nearest $0.1 \mathrm{~kg}$ with an electronic wheelchair scale accurate to $0.1 \mathrm{~kg}$ (Seca 664, Seca $\mathrm{GmbH}$, Hamburg, Germany). The guardian stood alone on the scale while the examiner clicked the tare button on the scale. This set the scale readout to zero. The child was then handed to the adult on the scale. In this way the scale recorded only the child's weight [19].

SL was measured by a non-elastic tape (Gima 27341, Gima S.p.A., Gessate, Italy) to the nearest $0.1 \mathrm{~cm}$ on the child's right side. Dietitian and caregivers positioned the child supine on an appropriate exam table with the Frankfort plane perpendicular to the table (support), shoulders and buttocks resting against the table, arms along the trunk, palms facing up, legs as straight as possible and in contact with the table (board). In cases of scoliosis and contractures, segmental lengths were taken three times from the top of the head to the greater trochanter of the hip, from the hip to the femoral epicondyle of the knee, and from the knee to the distal point of the calcaneus, were then added and the total mean measurement was recorded [13].

Body mass index (BMI) was calculated by the following formula: $\mathrm{BW}(\mathrm{kg}) / \mathrm{SL}^{2}\left(\mathrm{~m}^{2}\right)$.

$\mathrm{BW}, \mathrm{BL}$, and $\mathrm{BMI} \mathrm{z}$-scores were derived using the WHO Growth Charts [20]

A $\mathrm{z}$-score $<-1$ was considered under the normal range, between the -1 and +1 was considered normal, between the +1 and +2 was considered indicative of overweight, and a $\mathrm{z}$-score $>+2$ was considered indicative of obesity [20].

\section{Statistical analysis}

Most continuous variables were not normally distributed, and all are reported as median and interquartile range (IQR, 25th-75th percentile). Discrete variables are reported as the number and proportion of subjects with the characteristic of interest. The median values of anthropometric variables were compared between spontaneously breathing with mechanical ventilation children and mouth-fed and children with artificial feeding using the Wilcoxon Rank sum test. A value of $p<0.05$ was considered statistically significant. Statistical analysis was performed using IBM SPSS Statistics software version 26.0 for Windows (IBM, Armonk, NY, USA).

Derived SMA-specific growth percentiles curves were developed for SMA1 and SMA2 patients using the LMS method [21]. Sex-specific values by month of age were obtained for all anthropometric outcomes using the LMS method (LMS Chart Maker, Medical Research Council, UK) [21]. This statistical approach, widely used to construct reference data for traits which incorporate the effects of growth, provides three outputs: (a) a smoothed median ( $\mathrm{M}$ or $\mathrm{mu}$ ) curve which represents how the outcome varies in relation to age; (b) the coefficient of variation ( $\mathrm{S}$ or sigma), which models the scatter of values around the mean and adjusts for any non-uniform dispersion; and (c) the skewness ( $\mathrm{L}$ or lambda) which is addressed using age-specific Box-Cox transformation to achieve a normal distribution. The program also calculates centile values by age. BMI was fitted using original age, and weight and height using re-scaled age, which improves the goodness of fit for monotonic data by fitting the $\mathrm{M}$ curve twice. Goodness-of-fit was assessed with the Bayesian Information Criterion, adding an extra unit of complexity to the model only if it reduced the deviance by more than $\log _{e}(N)$ units, where $N$ is the sample size.

To compare these growth percentiles curves against WHO reference data, we superimposed centiles over the age range $0-5$ years for the SMA1 patients, and 0-10 years for the SMA2 patients. We plotted the 10th, 25th, 50th, 75th and 90th centiles for WHO, and the 10th, 25th, 50th, 75th and 90th centiles for the patient data. Further comparison between WHO-scores of SMA patients and the median of the reference population was accomplished by using one-sample $t$ tests. Data are reported as mean and confidence intervals (CI). A $p$ value $<0.05$ was considered statistically significant.

\section{Results}

We recruited 133 SMA1 children (56.4\% females and $43.6 \%$ males) and 82 SMA2 children (48.8\% females and $51.2 \%$ males) (Additional file 1: Fig. S1). Median ages were 0.6 (IQR: 0.4-1.6) and 4.1 (IQR: 2.1-6.7) years, respectively. Table 1 shows the distributions of demographic, clinical (ventilation, feeding) and anthropometric variables.

In SMA1 children, both BW and BMI z-scores were significantly lower in mechanically ventilated compared to spontaneously breathing patients $(-1.8$ vs. -1.0 , $p=0.003 ;-3.1$ vs. $-2.1, p \leq 0.001$; respectively), or in tube-fed compared to orally-fed patients $(-1.2$ vs. -2.2 , $p=0.012$; -3.4 vs. -2.2 ; $p=0.026$; respectively). Similarly, in SMA2 children, both BW and BMI z-score were significantly lower in the mechanically ventilated patients compared to those on spontaneous breathing $(-1.8$ vs. $-0.9, p=0.003 ;-2.9$ vs. $-0.8, p=0.019$; respectively).

\section{SMA1 growth patterns}

Additional file 2: Fig. S2 shows smoothed percentile curves of weight, supine length, and BMI-for-age for girls and boys with SMA1. Additional file 3: Table S1 shows the LMS values and percentile distributions for weight, supine length, and BMI-for-age of SMA1 patients. 
Table 1 Demographic, clinical and anthropometric variables in SMA1 and SMA2 children

\begin{tabular}{|c|c|c|c|c|c|c|}
\hline & \multicolumn{3}{|l|}{ SMA1 } & \multicolumn{3}{|l|}{ SMA2 } \\
\hline & Male & Female & Total & Male & Female & Total \\
\hline & $\mathrm{N}=58(43.6 \%)$ & $\mathrm{N}=75(56.4 \%)$ & $N=133$ & $\mathrm{~N}=42(51.2 \%)$ & $\mathrm{N}=40(48.8 \%)$ & $\mathrm{N}=82$ \\
\hline \multicolumn{7}{|l|}{$\begin{array}{l}\text { Demographic vari- } \\
\text { ables }\end{array}$} \\
\hline Age (years) & $0.7(0.4 ; 2.1)$ & $0.6(0.4 ; 1.4)$ & $0.6(0.4 ; 1.6)$ & $4.3(2.2 ; 7.0)$ & $3.9(1.9 ; 6.7)$ & $4.1(2.1 ; 6.7)$ \\
\hline \multicolumn{7}{|l|}{ Age classes } \\
\hline 0-1 year & $35(60.3 \%)$ & $51(68.0 \%)$ & $86(64.7 \%)$ & $1(2.4 \%)$ & $0(0.0 \%)$ & $1(1.2 \%)$ \\
\hline $1-3$ years & $14(24.1 \%)$ & $10(13.3 \%)$ & $24(18.0 \%)$ & $12(28.6 \%)$ & $15(37.5 \%)$ & $27(32.9 \%)$ \\
\hline $3-6$ years & 4 (6.9\%) & $8(10.7 \%)$ & $12(9.0 \%)$ & $15(35.7 \%)$ & $13(32.5 \%)$ & $28(34.1 \%)$ \\
\hline $6-10$ years & $3(5.2 \%)$ & $4(5.3 \%)$ & $7(5.3 \%)$ & $9(21.4 \%)$ & $10(25.0 \%)$ & $18(22.0 \%)$ \\
\hline$>10$ years & $2(3.5 \%)$ & $2(2.7 \%)$ & $4(3.0 \%)$ & $5(11.9 \%)$ & $2(5.0 \%)$ & $8(9.8 \%)$ \\
\hline \multicolumn{7}{|l|}{ Clinical variables } \\
\hline \multicolumn{7}{|l|}{ Ventilation } \\
\hline $\begin{array}{c}\text { Spontaneous } \\
\text { breathing }\end{array}$ & $58(63.8 \%)$ & $47(62.7 \%)$ & $85(63.3 \%)$ & $31(73.8 \%)$ & $26(65.0 \%)$ & $57(69.5 \%)$ \\
\hline $\begin{array}{l}\text { Non invasive- } \\
\text { ventilation }\end{array}$ & $13(22.4 \%)$ & $23(30.7 \%)$ & $36(27.1 \%)$ & $11(26.2 \%)$ & $14(35.0 \%)$ & $25(30.5 \%)$ \\
\hline Tracheostomy & $8(13.8 \%)$ & $5(6.6 \%)$ & $13(9.6 \%)$ & $0(0.0 \%)$ & $0(0.0 \%)$ & $0(0.0 \%)$ \\
\hline $\begin{array}{l}\text { Total mechanical } \\
\text { ventilation }\end{array}$ & $21(36.2 \%)$ & $28(37.3 \%)$ & $49(36.7 \%)$ & $11(26.2 \%)$ & $14(35.0 \%)$ & $25(30.5 \%)$ \\
\hline \multicolumn{7}{|l|}{ Feeding } \\
\hline By mouth & 48 (82.8\%) & $57(76.0 \%)$ & 105 (79.0\%) & $42(100.0 \%)$ & 40 (100.0\%) & $82(100.0 \%)$ \\
\hline Nasogastric tube & $1(1.7 \%)$ & $5(6.7 \%)$ & $6(4.5 \%)$ & $0(0.0 \%)$ & $0(0.0 \%)$ & $0(0.0 \%)$ \\
\hline $\begin{array}{l}\text { Percutaneous } \\
\text { endoscopic } \\
\text { gastrostomy }\end{array}$ & $9(15.5 \%)$ & $13(17.3 \%)$ & $22(16.5 \%)$ & $0(0.0 \%)$ & $0(0.0 \%)$ & $0(0.0 \%)$ \\
\hline $\begin{array}{l}\text { Total artificial } \\
\text { feeding }\end{array}$ & $10(17.2 \%)$ & $18(24.0 \%)$ & $28(21.0 \%)$ & $0(0.0 \%)$ & $0(0.0 \%)$ & $0(0.0 \%)$ \\
\hline \multicolumn{7}{|l|}{$\begin{array}{l}\text { Anthropometric } \\
\text { variables }\end{array}$} \\
\hline Weight (kg) & $7.2(6.2 ; 9.1)$ & $7.4(6.2 ; 9.3)$ & $7.4(6.2 ; 9.2)$ & $14.4(11.5 ; 19.2)$ & $13.6(10.4 ; 20.0)$ & $14.2(10.7 ; 19.8)$ \\
\hline $\begin{array}{l}\text { Weight z-score } \\
\text { (WHO) }\end{array}$ & $\begin{array}{l}-1.64(-2.39 \\
-0.69)\end{array}$ & $\begin{array}{l}-0.72(-1.73 \\
-0.05)\end{array}$ & $\begin{array}{l}-1.01(-2.17 \\
-0.12)^{* \delta}\end{array}$ & $\begin{array}{l}-1.04(-2.26 \\
-0.24)\end{array}$ & $\begin{array}{l}-1.06(-2.17 \\
-0.36)\end{array}$ & $\begin{array}{l}-1.04(-2.26 \\
-0.33)^{*}\end{array}$ \\
\hline Length (m) & $0.72(0.67 ; 0.86)$ & $0.72(0.66 ; 0.82)$ & $0.72(0.66 ; 0.84)$ & $1.05(0.89 ; 1.17)$ & $0.97(0.84 ; 1.11)$ & $1.02(0.87 ; 1.15)$ \\
\hline $\begin{array}{l}\text { Length z-score } \\
(\mathrm{WHO})\end{array}$ & $0.54(-0.28 ; 1.50)$ & $1.03(-0.17 ; 1.99)$ & $0.82(-0.15 ; 1.80)$ & $-0.17(-0.78 ; 1.20)$ & $-0.62(-2.12 ; 0.69)$ & $0.41(-1.78 ; 0.83)$ \\
\hline BMI $\left(\mathrm{kg} / \mathrm{m}^{2}\right)$ & $13.4(12.1 ; 14.9)$ & $13.9(12.7 ; 14.9)$ & $13.7(12.3 ; 14.9)$ & $14.1(12.6 ; 15.9)$ & $14.1(13.2 ; 15.9)$ & $14.1(12.8 ; 15.9)$ \\
\hline BMI z-score (WHO) & $\begin{array}{l}-2.61(-3.87 \\
-1.72)\end{array}$ & $\begin{array}{l}-2.22(-3.19 \\
-1.08)\end{array}$ & $\begin{array}{l}-2.48(-4.17 \\
-1.43)^{* \delta}\end{array}$ & $\begin{array}{l}-1.23(-2.91 \\
-0.35)\end{array}$ & $\begin{array}{l}-0.75(-1.93 \\
-0.45)\end{array}$ & $\begin{array}{l}-1.28(-2.61 \\
-0.13)^{*}\end{array}$ \\
\hline
\end{tabular}

Data are presented as median and interquartile range (IQR) for continuous measures, and $\mathrm{n}(\%)$ for categorical measures $B M /$ body mass index (Body Weight $(\mathrm{kg}) /$ Body Length $\left(\mathrm{m}^{2}\right)$ )

${ }^{*} p<0.050$ Spontaneous breathing versus mechanical ventilation

${ }^{\delta} p<0.050$ Fed by mouth versus total artificial feeding

Weight and supine length growth are more linear in SMA1 girls compared to SMA1 boys, who show a decrease in weight, length, and BMI velocity at about 3 years of age.

\section{SMA2 growth patterns}

Additional file 4: Fig. S3 shows smoothed percentile curves of weight, supine length, and BMI-for-age for girls and boys with SMA2. Additional file 5: Table S2 shows 
the LMS values and percentile distributions for weight, supine length, and BMI-for-age of SMA1 patients.

SMA2 girls have a linear weight and length growth velocity, while SMA2 boys show a decrease in both weight and length velocity since about 6 years of age.

\section{Comparisons between WHO and SMA growth percentiles}

Figures 1 and 2 show graphical comparisons of body weight, supine length, and BMI-for-age between WHO growth percentiles and SMA1 and SMA2 patients, respectively.

In SMA1, weight is significantly lower than healthy peers in both sexes and at all age classes [mean WHO $\mathrm{z}$-score -1.334 (CI -1.608 to -1.071$) ; p \leq 0.001$ ], while supine length is more variable. SMA1 girls are longer than their healthy peers up to the age of 1 year [mean WHO z-score 1.02 (CI 0.550-1.491); $p \leq 0.001$ ], and then they follow more closely the growth pattern of the general pediatric population [mean WHO z-score 0.049 (CI -0.556 to 0.656$) ; p=0.869$ ]. Supine length is similar to the general pediatric population in boys in all age classes [mean WHO z-score 0.313 (CI -0.161 to 0.787 ); $p=0.192]$. BMI is lower for both sexes in all age classes (mean WHO z-score -2.339 ; CI -2.643 to -2.034 ; $p<0.001)$.

In SMA2, weight is generally lower in both sexes up to 6 years (mean WHO z-score -1.084 (CI -1.419 to $-0.749) ; p \leq 0.001$ ), when it starts to follow the growth pattern of the general pediatric population [mean WHO $\mathrm{z}$-score -0.663 (CI -1.544 to 0.219$) ; p=0.132$ ]. There is a small proportion of boys who are heavier [ 5 patients, $6 \%$ of SMA2 sample; mean WHO z-score 1.654 (CI 1.5431.906)]. Supine length is similar to the general pediatric population in boys [mean WHO z-score -0.292; $(\mathrm{CI}-0.792$ to 0.208$) ; p=0.244$ ] and girls [mean WHO z-score -0.531 (CI -1.616 to 0.555 ); $p=0.310$ ], but shorter in girls from 3 years [mean WHO z-score -0.982 (CI -1.421 to -0.543$) ; p \leq 0.001]$. BMI is also typically lower in both sexes up to 6 years [mean WHO z-score -1.262 (CI -1.666 to -0.857 ); $p=0.000$ ] and similar to the general pediatric population afterwards [mean WHO $\mathrm{z}$-score -0.388 (CI -1.515 to 0.738 ); $p=0.481$ ], except for boys which are heavier at older ages [mean WHO z-score 1.534 (CI 1.293-1.902); $p=0.048$; mean age 7 (5.0-9.3) years].

A Z-score calculator and printable PDFs of SMA growth percentiles curves can be used as a further aid (https://jscalc.io/calc/Q91zp6clkwI9PVBn).

\section{Discussion}

This study provides, for the first time, growth curves derived from a large, well-characterized sample of treatment-naïve SMA1 and SMA2 children. These data were collected as part of a large natural history cohort study in 5 Italian centers, where patients were regularly monitored and followed up according to the SoC for SMA $[5,14]$, and using a standardized and validated protocol of anthropometric measures on SMA [18]. Over the past decade, the implementation of $\mathrm{SoC}$ in the management of patients with SMA has strongly improved their survival and quality of life. Additionally, the approval of disease-modifying treatments by the US Food and Drug Administration and the European Medicines Agency, and their increasing availability to patients in many countries are gradually changing the natural history of the disease $[15,22]$. For this reason, the availability of reference data in treatment-naive patients can be particularly helpful and timely to assess the efficacy of the available and forthcoming therapies not only on motor function and survival, but also on other domains, including growth and nutritional status [23].

To date, few studies have investigated the nutritional aspects in SMA [8, 13, 24-27], all of them being on small samples and few using a standardized protocol to assess growth pattern [28]. When compared to WHO percentiles, the present study confirms that in SMA1 weight is significantly lower than healthy peers in both sexes and at all ages, as consistently reported in previous studies $[8,13]$. Although the numbers were limited to split the sample into different categories of severity based on the clinical presentation (symptoms in the first 2 weeks of life [type $1 \mathrm{~A}$ ], within the third month [type 1B], and between 3 and 6 months [type 1C]) [29,30], our data show that patients at the most severe end of the spectrum, requiring respiratory and nutritional support, are those who had lower weight. Importantly, SMA2 patients have lower weight than the general pediatric population since the first years of life, and those requiring non-invasive ventilatory support are also those having lower weight. These differences should be taken into consideration when monitoring nutritional status in SMA children, as they can be helpful in guiding and customizing early nutritional intervention in this population. Of note, we found that SMA1 children had an above average SL compared to the general pediatric population, while BMI tended to be significantly lower, consistent with the weight pattern. This could be due to the fact that we used segmental length because of the possible presence of contractions, inability to stand, scoliosis and other musculo-skeletal deformities, and this may have resulted in overestimates, despite having used a standardized method [13, 18].

Our findings confirm that BMI references based on the general pediatric population are not good indicators of the nutritional status in SMA children as they show a growth pattern which is specific to the condition. This is further supported by previous studies by us and others 


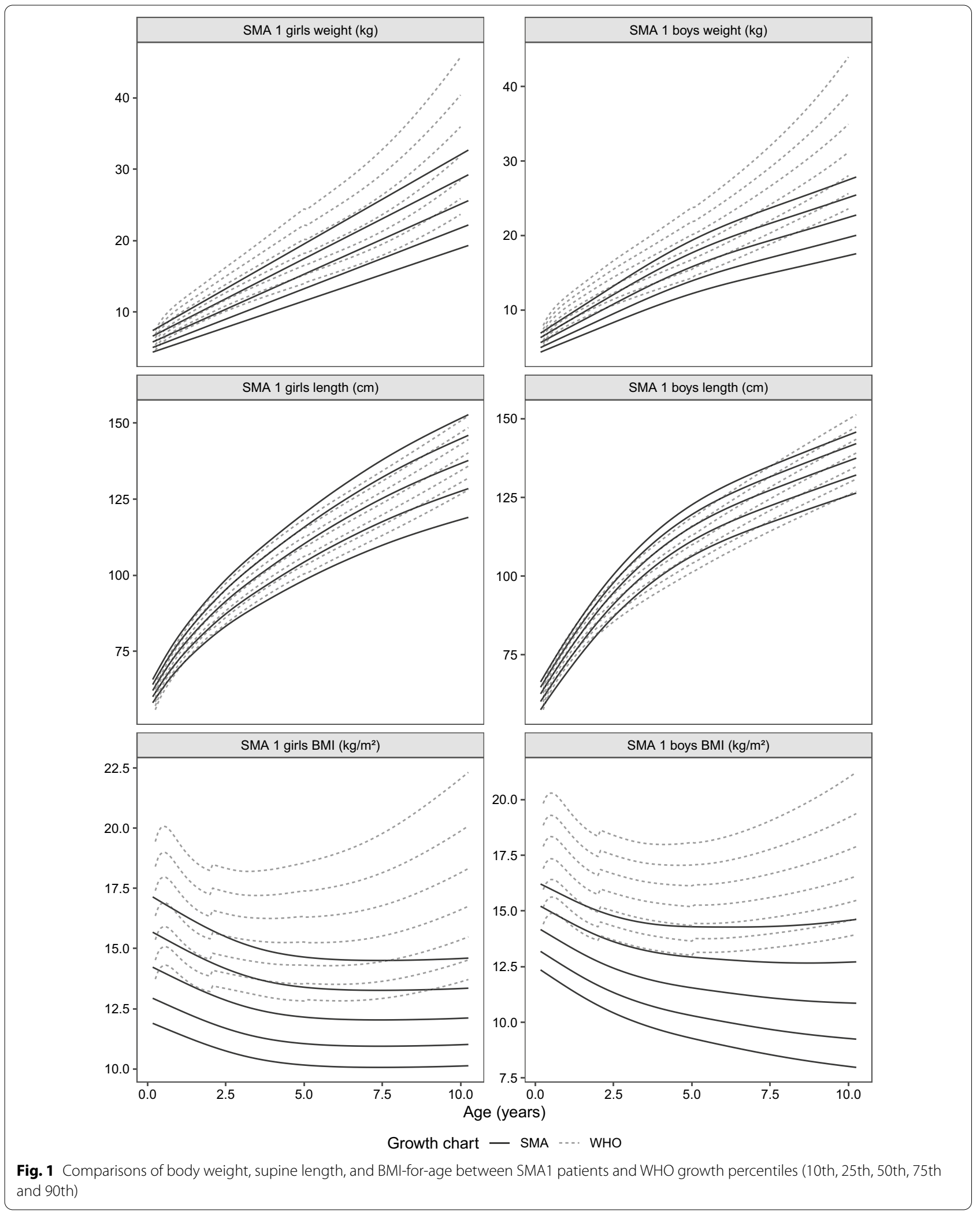




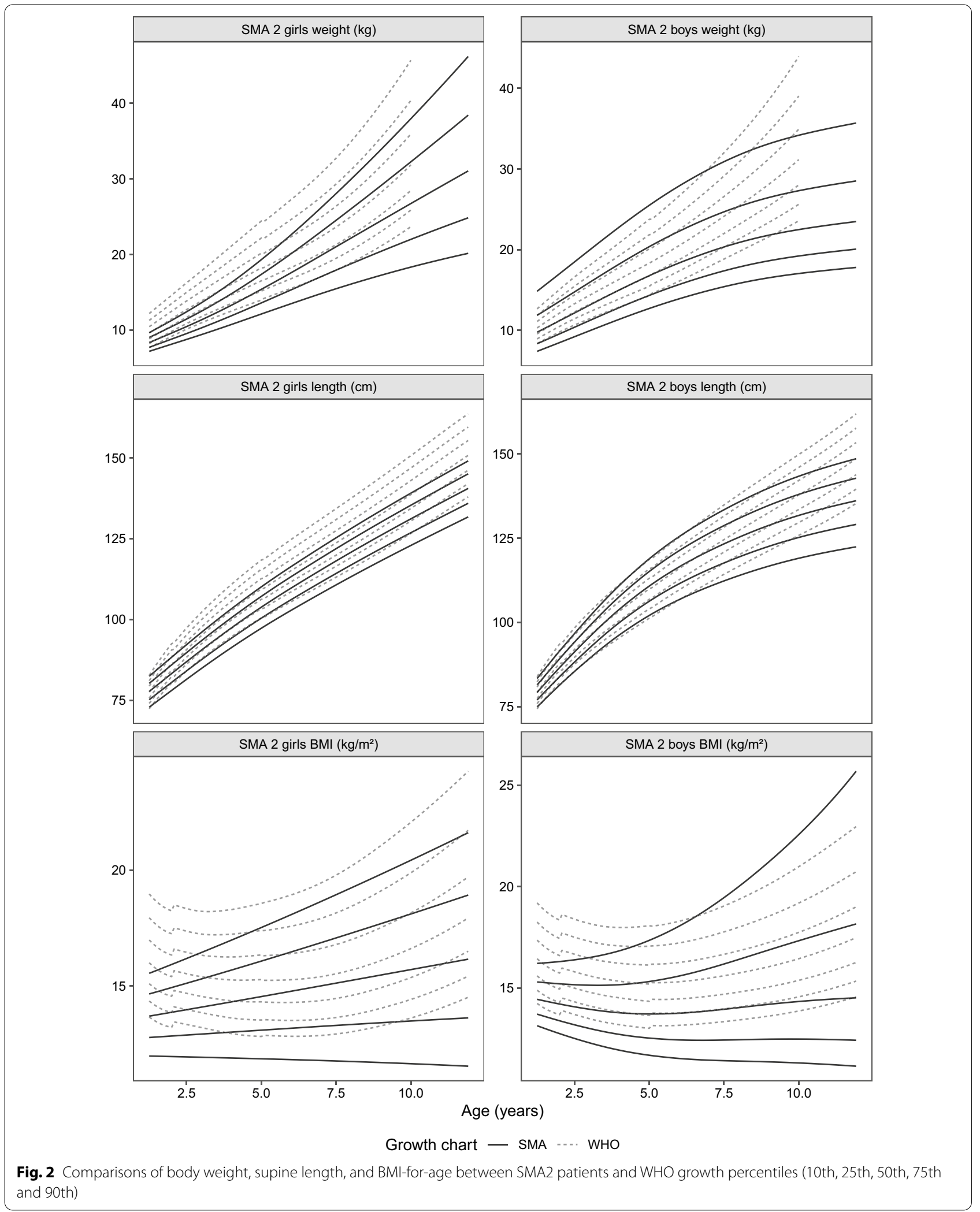


showing that fat mass is increased, and total fat-free mass and lean mass decreased in both SMA1 and SMA2 compared to healthy peers, with fat mass increasing with age $[10,12,13,25-27]$. Furthermore, we have also shown that body composition mildly to moderately correlates with motor function depending on the clinical phenotype [10]. The risk of sub-optimal nutritional management in children with SMA, with adverse effects on their body composition and nutritional status and ultimately their functional abilities, can be at least partly overcome using disease-specific growth percentiles curves.

Interestingly, we have also identified the presence of gender differences in the growth pattern of SMA children: weight and supine length growth are more linear in girls compared to boys, with SMA1 boys having a decrease in weight, length, and BMI velocity, and a small proportion of SMA2 boys (6\% of our SMA2 sample) showing constantly a higher body weight then the general pediatric population. In an animal model, SMA females displayed better therapeutic outcomes than SMA male mice and a better functional response [28], but further studies are needed to better understand the sex-dependent influence on disease progression, pathophysiology, and response to treatment [28]. Our findings further highlight the role that gender plays in determining sexspecific variations and vulnerabilities in SMA and may have important clinical implications to customize the nutritional management since diagnosis.

This study has several strengths. The age distribution of the sample allowed us to have cross-sectional data in treatment-naïve patients. This could be crucial to potentially investigate the effect of drugs on all the collected parameters in different age groups. Secondly, this is the largest work in the literature studying nutritional status in children with a confirmed diagnosis of SMA. The third strength is the data quality: these data were collected prospectively through a standardized protocol [17], and not retrospectively from chart reviews; dispersion of patients was overcome by strict cooperation between the involved centers that also allowed an equal distribution in the different classes of age. Moreover, we have developed easily accessible and printable percentiles curves that could be implemented in the clinical practice.

A possible limitation of the study is that all children were Caucasian, and their patterns of nutritional status may not be globally representative of all ethnic groups. Furthermore, as this is a cross-sectional and not a longitudinal study, we could not investigate the growth patterns of individual SMA children: the sample size was not large enough to build a model of growth, in spontaneously breathing and mouth-fed children and in children with mechanical ventilation and/or tube feeding. Moreover, due to the low number of breastfed children $(6 \%$ of total sample), the different types of feeding (breastfeeding, formula feeding or mixed feeding) were also not taken into account despite it is well documented that the growth patterns of breast-fed and formula-fed infants differ significantly [31, 32]. The clinical diagnosis of SMA was made in accordance with the first version of the SoC recommendations [16], because the recruitment took place between April 2015 and May 2018: for this reason, the percentiles were divided by SMA1 and SMA2 and not according to the functional classification reported in the 2018 update of the SoC recommendations, which classifies SMA patients as sitters and non-sitters; also, SMN2 copy number was not systematically collected in our study. Further studies in children receiving diseasemodifying treatments will allow comparisons also based on the motor functional classification and SMN2 copy number. Moreover, how spine and joint deformity could potentially affect growth pattern will require further investigation in future studies. Finally, the number of growth measurements was small at the older ages, which may limit the precision of the estimates at those ages.

Key questions still remain unanswered and will require further investigations in the future: (1) how the new disease-modifying treatments will impact the nutritional status of children with SMA by promoting the development of new phenotypes with preserved swallowing and respiratory function, particularly when treatment is administered at a pre-symptomatic or early postsymptomatic phase; (2) how weight and height influence other aspects of the disease, including general health, respiratory status, cardiac and metabolic status, risk for fractures and/or scoliosis; (3) how feeding type (breastfeeding, formula, mixed feeding), demographic and socioeconomical status (urban and rural areas, medical level, economic level, family care, education, etc.) could affect growth pattern in SMA disease.

\section{Conclusion}

Nutritional aspects play a significant role in the multidisciplinary management of children with SMA1 and SMA2, particularly in the treatment of nutritional derangements including swallowing and gastrointestinal problems. The increase in the knowledge on nutritional aspects of patients with SMA is crucial for the appropriate management of patients. However, the lack of specific, standardized and coordinated nutritional assessment for SMA patients [28] is common and the use of reference data [20] developed for healthy children increases the risk of inadequate nutritional support because of the peculiar nature of SMA $[5,9]$.

These data on treatment-naïve patients point toward a better understanding of the natural progression of the disease, to improve the clinical and nutritional 
management of patients and to evaluate the effects of disease-modifying treatments on growth in SMA1 and SMA2.

\author{
Abbreviations \\ BMI: Body mass index; BW: Body weight; Cl: Confidence interval; SL: Supine \\ length; SMA: Spinal muscular atrophy; SMA1: Spinal muscular atrophy type 1 ; \\ SMA2: Spinal muscular atrophy type 2; SMN1: Survival of motor neuron 1; SoC: \\ Standard of care; WHO: World Health Organization.
}

\section{Supplementary Information}

The online version contains supplementary material available at https://doi. org/10.1186/s13023-021-02015-9.

Additional file 1: Fig. S1. Participant flow chart.

Additional file 2: Fig. S2. Body weight, supine length, and BMI-for-age percentile curves (10th, 25th, 50th, 75th and 90th) of SMA1 patients.

Additional file 3: Table S1. Observed means, SD and percentile distributions for weight, supine length, and BMI-for-age of SMA1 patients.

Additional file 4: Figure S3. Body weight, supine length, and BMl-for-age percentile curves (10th, 25th, 50th, 75th and 90th) of SMA2 patients.

Additional file 5: Table S2. Observed means, SD and percentile distributions for weight, supine length, and BMI-for-age of SMA2 patients.

\section{Acknowledgements}

We would like to thank the dietitians that took part in data collection for the multicentric study: dr. Veronica Boscolo and dr. Antonella Lorubbio. We also thank all the SAPRE's staff (Katia Alberti, Mirea Negri, Grazia Zappa, Myriam Rauso) who helped in the patients' recruitment and families and children who participated in this study.

\section{Authors' contributions}

The research was designed by $S B, A B, R D$ and conducted by $S B$ and $R D ; R D, A F$ and $S R$ collected all the data; RD, AL, AF, JW performed statistical analysis; $R D$ also wrote the draft of manuscript; SB, GiBa and MF contributed to manuscript editing and critically evaluated the manuscript; $C M, G i B a, C B, M P, E B, A D, E G$ enrolled the sample subjects; GiBe helped with the data interpretation and revised the manuscript. All authors read and approved the final manuscript..

\section{Funding}

Support for this study was given by the Italian Association of SMA Families (Famiglie SMA, 2015-2016 contribution) and by Fondazione Telethon (Application GUP15014, 2015, Italy).

\section{Availability of data and materials}

The corresponding authors will cooperate with any reasonable requests from the journal for data or additional information should questions about the paper arise after publication.

\section{Declarations}

\section{Ethics approval and consent to participate}

The study was approved by the Ethics Committee of the University of Milan (n.7/16), accepted by the other institutional partners and complied following the Helsinki declaration. The parents, on behalf of their children, gave their written informed consent to the study.

\section{Consent for publication}

Not applicable.

\section{Competing interests}

Some authors (EB, CA, CB, AD, MP) are members of the European Reference Network for Neuromuscular Diseases (ERN EURO-NMD). GiBa has received speaker and consultancy honoraria from AveXis, Inc., Roche, PTC, and Sarepta Therapeutics, but he received no funding for this specific study. All the other authors have no conflicts of interest relevant to this article to disclose.

\section{Author details}

${ }^{1}$ International Center for the Assessment of Nutritional Status (ICANS), Department of Food, Environmental and Nutritional Sciences (DeFENS), University of Milan, Via Sandro Botticelli 21, 20133 Milan, Italy. ${ }^{2}$ UO Neurologia dello Sviluppo, Fondazione IRCCS Istituto Neurologico Carlo Besta, Milan, Italy. ${ }^{3}$ The Dubowitz Neuromuscular Centre, UCL NIHR GOSH Biomedical Research Centre, UCL Great Ormond Street Institute of Child Health, London, UK. ${ }^{4}$ Dietetic and Nutrition Center, M. Bufalini Hospital, Cesena, Italy. ${ }^{5}$ SAPREUONPIA, Fondazione IRCCS Ca'Granda Ospedale Maggiore Policlinico, Milan, Italy. ${ }^{6}$ Dipartimento di Salute della Donna e del Bambino, Università di Padova, Padua, Italy. ${ }^{7}$ Unità di Malattie Neuromuscolari e Neurodegenerative, Laboratorio di Medicina Molecolare, Dipartimento di Neuroscienze e Neuroriabilitazione, IRCCS Ospedale Pediatrico Bambino Gesù, Rome, Italy. ${ }^{8}$ Pediatric Neurology and Muscle Disease Unit, IRCCS Istituto Giannina Gaslini, Genoa, Italy. ${ }^{9}$ Center of Translational and Experimental Myology, IRCCS Istituto Giannina Gaslini, Genoa, Italy. ${ }^{10}$ Childhood Nutrition Research Group, Population, Policy and Practice Research and Teaching Department, UCL Great Ormond Street Institute of Child Health, London, UK. ${ }^{11}$ Obesity Unit and Laboratory of Nutrition and Obesity Research, Department of Endocrine and Metabolic Diseases, IRCCS Istituto Auxologico Italiano, Milan, Italy.

Received: 28 May 2021 Accepted: 24 August 2021

Published online: 04 September 2021

\section{References}

1. Kolb SJ, Kissel JT. Spinal muscular atrophy: a timely review. JAMA Neurol. 2011;68:979-84.

2. Lefebvre S, Burglen L, Reboullet S, Clermont O, Burlet P, Viollet L, et al. Identification and characterization of a spinal muscular atrophy-determining gene. Cell. 1995;80:155-65.

3. Verhaart IEC, Robertson A, Wilson IJ, Aartsma-Rus A, Cameron S, Jones $C C$, et al. Prevalence, incidence and carrier frequency of 5q-linked spinal muscular atrophy — a literature review. Orphanet J Rare Dis. 2017;12:124. https://doi.org/10.1186/s13023-017-0671-8.

4. Keinath MC, Prior DE, Prior TW. Spinal muscular atrophy: mutations, testing, and clinical relevance. Appl Clin Genet. 2021;14:11-25.

5. Mercuri E, Finkel RS, Muntoni F, Wirth B, Montes J, Main M, et al. Diagnosis and management of spinal muscular atrophy: Part 1: recommendations for diagnosis, rehabilitation, orthopedic and nutritional care. Neuromuscul Disord. 2018:28:103-15.

6. Finkel RS, Mercuri E, Darras BT, Connolly AM, Kuntz NL, Kirschner J, et al. Nusinersen versus sham control in infantile-onset spinal muscular atrophy. N Engl J Med. 2017;377:1723-32.

7. Messina S, Pane M, De Rose P, Vasta I, Sorleti D, Aloysius A, et al. Feeding problems and malnutrition in spinal muscular atrophy type II. Neuromuscul Disord. 2008;18:389-93.

8. Poruk KE, Davis RH, Smart AL, Chisum BS, Lasalle BA, Chan GM, et al. Observational study of caloric and nutrient intake, bone density, and body composition in infants and children with spinal muscular atrophy type I. Neuromuscul Disord. 2012;22:966-73.

9. Bertoli S, De Amicis R, Mastella C, Pieri G, Giaquinto E, Battezzati A, et al. Spinal muscular atrophy, types I and II: What are the differences in body composition and resting energy expenditure? Clin Nutr. 2017;36:1674-80

10. Baranello G, De Amicis R, Arnoldi MT, Zanin R, Mastella C, Masson R, et al. Evaluation of body composition as a potential biomarker in spinal muscular atrophy. Muscle Nerve. 2020;61:530-4.

11. D'Amico A, Mercuri E, Tiziano FD, Bertini E. Spinal muscular atrophy. Orphanet J Rare Dis. 2011;6:71.

12. Sproule DM, Montes J, Montgomery M, Battista V, Koenigsberger D, Shen W, et al. Increased fat mass and high incidence of overweight despite low body mass index in patients with spinal muscular atrophy. Neuromuscul Disord. 2009;19:391-6.

13. Sproule DM, Montes J, Dunaway S, Montgomery M, Battista V, Koenigsberger $D$, et al. Adiposity is increased among high-functioning, 
non-ambulatory patients with spinal muscular atrophy. Neuromuscul Disord. 2010;20:448-52.

14. Finkel RS, Mercuri E, Meyer OH, Simonds AK, Schroth MK, Graham RJ, et al. Diagnosis and management of spinal muscular atrophy: Part 2: pulmonary and acute care; medications, supplements and immunizations; other organ systems; and ethics. Neuromuscul Disord. 2018;28:197-207.

15. Singh RN, Ottesen EW, Singh NN. The first orally deliverable small molecule for the treatment of spinal muscular atrophy. Neurosci Insights. 2020:15:2633105520973985.

16. Baranello G, Darras BT, Day JW, Deconinck N, Klein A, Masson R, et al. Risdiplam in type 1 spinal muscular atrophy. N Engl J Med. 2021;384:915-23.

17. Wang CH, Finkel RS, Bertini ES, Schroth M, Simonds A, Wong B, et al. Consensus statement for standard of care in spinal muscular atrophy. J Child Neurol. 2007;22:1027-49.

18. Bertoli S, Foppiani A, De Amicis R, Leone A, Mastella C, Bassano M, et al. Anthropometric measurement standardization for a multicenter nutrition survey in children with spinal muscular atrophy. Eur J Clin Nutr. 2019;73(12):1646-8.

19. WHO child growth standards: training course on child growth assessment. [Internet]. World Heal. Organ. 2008 [cited 2021 May 12]. Available from: https://www.who.int/childgrowth/training/module_b_measuring_ growth.pdf.

20. de Onis M, Onyango AW, Van den Broeck J, Chumlea WC, Martorell R. Measurement and standardization protocols for anthropometry used in the construction of a new international growth reference. Food Nutr Bull. 2004:25:\$27-36

21. Cole TJ, Freeman JV, Preece MA. British 1990 growth reference centiles for weight, height, body mass index and head circumference fitted by maximum penalized likelihood. Stat Med. 1998;17:407-29.

22. Mercuri E, Darras BT, Chiriboga CA, Day JW, Campbell C, Connolly AM, et al. Nusinersen versus sham control in later-onset spinal muscular atrophy. N Engl J Med. 2018;378:625-35.

23. Gavin P. The importance of natural histories for rare diseases. Expert Opin Orphan Drugs. 2015;3:855-7.

24. Mehta NM, Newman H, Tarrant S, Graham RJ. Nutritional status and nutrient intake challenges in children with spinal muscular atrophy. Pediatr Neurol. 2016;57:80-3.
25. Cutillo L, Pizziconi C, Tozzi AE, Verrillo E, Beatrice M, Testa C, et al. Predicted and measured resting energy expenditure in children with spinal muscular atrophy 2. J Pediatr. 2014;164(5):1228-30.

26. Davis RH, Godshall BJ, Seffrood E, Marcus M, LaSalle BA, Wong B, et al. Nutritional practices at a glance: spinal muscular atrophy type I nutrition survey findings. J Child Neurol. 2014;29:1467-72.

27. Foppiani A, De Amicis R, Leone A, Ravella S, Bedogni G, Battezzati A, et al. Predictive fat mass equations for spinal muscular atrophy type I children: development and internal validation. Clin Nutr. 2021;40(4):1578-87.

28. Moore GE, Lindenmayer AW, McConchie GA, Ryan MM, Davidson ZE. Describing nutrition in spinal muscular atrophy: a systematic review. Neuromuscul Disord. 2016;26:395-404.

29. Finkel R, Bertini E, Muntoni F, Mercuri E. 209th ENMC international workshop: outcome measures and clinical trial readiness in spinal muscular atrophy 7-9 November 2014, Heemskerk, The Netherlands. Neuromuscul Disord. 2015;7:593-602

30. LoMauro A, Mastella C, Alberti K, Masson R, Aliverti A, Baranello G. Effect of nusinersen on respiratory muscle function in different subtypes of type 1 spinal muscular atrophy. Am J Respir Crit Care Med. 2019:12:1547-50.

31. Dewey KG. Infant feeding and growth BT. In: Goldberg G, Prentice A, Prentice A, Filteau S, Simondon K, editors. Breast-feeding: early influences on later health. Dordrecht: Springer, Netherlands; 2009. p. 57-66. https:// doi.org/10.1007/978-1-4020-8749-3_5.

32. Burklin A, Wilson K, Lovelady C, Kramer MS, Guo T, Platt RW, et al. Infant growth and health outcomes associated with 3 compared with 6 mo of exclusive breastfeeding. FASEB J. 2003:31:291-5.

\section{Publisher's Note}

Springer Nature remains neutral with regard to jurisdictional claims in published maps and institutional affiliations.
Ready to submit your research? Choose BMC and benefit from:

- fast, convenient online submission

- thorough peer review by experienced researchers in your field

- rapid publication on acceptance

- support for research data, including large and complex data types

- gold Open Access which fosters wider collaboration and increased citations

- maximum visibility for your research: over $100 \mathrm{M}$ website views per year

At BMC, research is always in progress.

Learn more biomedcentral.com/submissions 